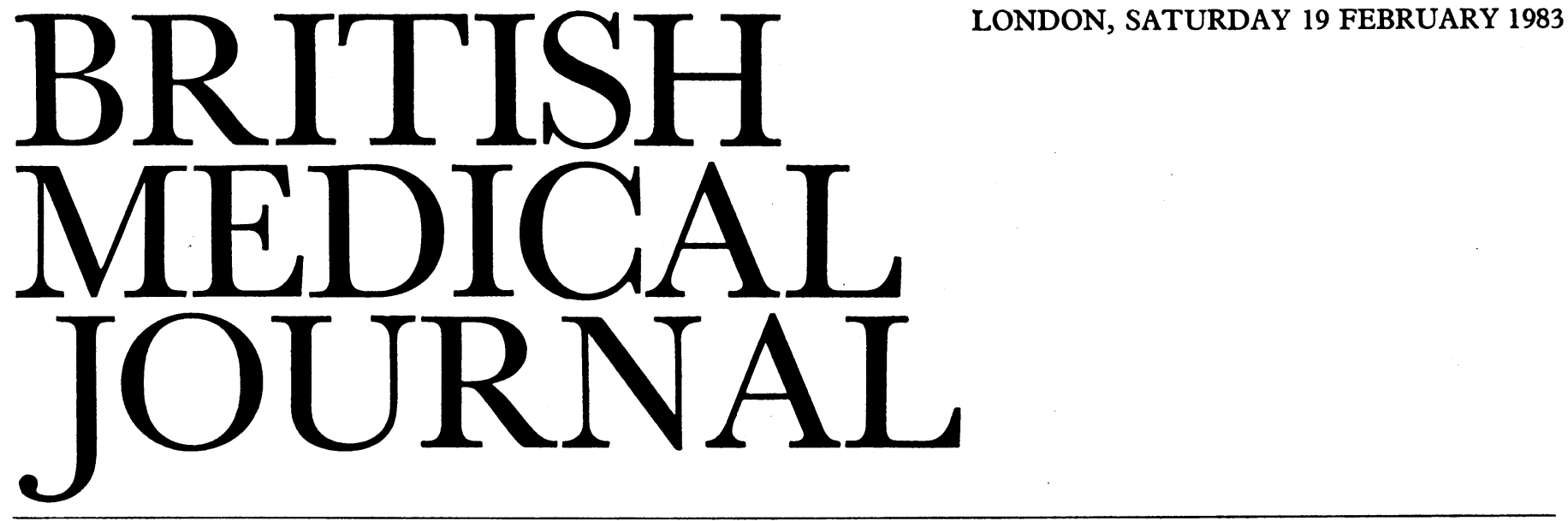

\title{
Doctors and the drug industry
}

Twelve months ago the $B M \mathcal{F}$ was sent a report of five deaths from liver failure in elderly patients who had been taking benoxaprofen. Publication of the report ${ }^{1}$ precipitated what journalists have called "the Opren scandal" and led to a sustained public discussion of the pharmaceutical industry and its relations with doctors and the NHS.

The man in the street has been told that prescription drugs are too expensive and are prescribed too readily by doctors, that many of these drugs are unsafe, and that the companies that sell them are greedy and corrupt. The industry has responded by assertions of innocence and concern for the public good, while doctors mostly seem to have hoped that the affair would blow over like previous alarms about drug safety.

We believe that both doctors and the pharmaceutical industry should stop justifying their current practices and look objectively at the charges that have been made-and the remedies suggested-by outside critics. At the outset we must admit that some of the drug promotion activities highlighted in recent journalistic investigations are blatant examples of the unacceptable face of capitalism. Nevertheless, we shall continue to remind critics of the drug industry that its commercial enterprise and competitiveness have produced almost all the important innovations in therapeutics since the second world war. Against that background, how justified are the recent accusations?

Firstly, are too many drugs prescribed? The answer, plainly, is yes. Tranquillisers and hypnotics are prescribed and represcribed for patients with complaints that should be tackled in other ways; antibiotics are widely used in prophylaxis with no sound justification; histamine receptor antagonists are given to patients with all sorts of dyspepsia with no real attempt at diagnosis; steroid ointments are given to too many patients with rashes. Can anyone believe that now that antiviral drugs have come on to the market they will be prescribed any more rationally and effectively?

Secondly, are the drugs too expensive? Costs of individual drugs in Britain are generally in line with those in other European countries-but the pharmaceutical price regulation scheme could be tightened up and close attention paid to apparent anomalies between Britain and her neighbours. Public perceptions of the size of the NHS drug bill are well out of line with reality. Most people think that drugs account for $30 \%$ or more of the total cost of the $\mathrm{NHS}^{2}$; the true figure is $10 \%$. Nevertheless, even a marginal saving in an annual bill of $£ 1200$ million is a lot of money, so that the Government is intent on making economies. One solution offered by the Greenfield committee ${ }^{3}$ (and being vigorously canvassed inside and outside Parliament) is generic substitution-a concept that would save some money but would have very real drawbacks. The pharmaceutical industry has been quick to point to the disproportionate effect such a policy would have on its earnings, since most generics are manufactured abroad. Investment in the industry, especially by multinational companies, would possibly be cut. Patients might be affected, too: those having long term treatment might, over the months, get tablets (of varying shapes and colours) from several different manufacturers-with all the confusion that might cause, especially if unexpected side effects occurred. Finally, generic substitution would create its own bureaucracy, for the DHSS would have to introduce some monitoring machinery for quality control of drugs from abroad.

Surely the focus of attention should be moved from the cost of the prescription (could a cheaper manufacturer be found ?) to the choice of prescription (is there a cheaper drug and does the patient need the drug at all ?). More effective prescribing could save the NHS a lot of money and benefit patients at the same time. Here the Greenfield proposals for providing doctors with detailed information on their own prescribing could lay the basis for self auditing schemes tied in with continuing education. At present neither doctors nor patients have any real incentive to look at the relative costs of similar drugs. If a doctor believes and his patient agrees that they want to use an expensive product when cheaper ones are available should the NHS foot the whole bill? Why not abolish prescription charges and introduce a surcharge for prescriptions costing over a certain figure?

The third question in the public mind is safety. The Minister of Health, Mr Kenneth Clarke, recently told MPs that all effective drugs have side effects" and that "it will never be possible to produce and market a new drug that is $100 \%$ safe." He failed to recognise, however, that the use by doctors of new drugs is the main conflict between medical prudence and commercial pressures. Clinicians know that the drugs least likely to have unexpected side effects are those they have used for longest (though in the case of practolol the association between the drug and its side effects took some years to unravel). The drug industry tries hard to persuade doctors to prescribe new products-in part because of the 
relatively short time of patent protection. The reality is that, just as the most dangerous part of an aircraft flight is at take off (and landing), so is a drug generally most dangerous in its first year or so of clinical use. Benoxaprofen made the headlines largely because hundreds of thousands of patients were prescribed the drug in that dangerous first year. It may be a statement of the obvious that had fewer patients taken benoxaprofen fewer would have been damaged, ${ }^{5}$ but scandals are made by numbers.

As we have argued before, ways must be found to set some limit to the uptake of drugs in their first year or so on the market (with a compensatory extension of patent life). ${ }^{5}$ More important, any doctor who makes the clinical decision to use a new drug should recognise that by so doing he is under an ethical obligation to keep full notes and record and report any adverse event, whether or not it seems likely to be linked with the drug. Doctors should not expect payment for that record keeping; indeed, if they do not keep such records they are, in our view, negligent.

These arguments have been rehearsed before. The new feature of the drug debate is its emphasis on advertising and promotion. Some doctors, at least, recognise that their professional image is being tarnished by their apparent financial thralldom to the pharmaceutical industry-and the industry is beginning to see that its own image needs to be improved if politicians are to be restrained from trying to control or curb expenditure on promotion.

What are the causes for concern? Complaints about drug advertising in journals and by direct mail are mostly confined to the frequency and numbers of these advertisements. Recent attempts by some companies to promote drugs by feeding information directly to the public have been heavily criticised and seem unlikely to be repeated. More serious doubts are raised by the close links between the pharmaceutical industry and the design and analysis of clinical trials of its products and by publication of reports of drug research in journals with no system of peer review. And what has angered the consumer watchdogs are the drug company sponsored concerts, banquets, and excursions. How has the medical profession come to expect that not only should its postgraduate education be financed by an interested partythe drug industry - but that the industry should also pay for much of doctors' foreign travel and entertainment?

Surely the time has come for the medical profession and the pharmaceutical industry to extend the agreed code of practice $^{6}$ by setting reasonable boundaries for expenditure on drug promotion? A joint, non-governmental, committee might be set up to provide guidance and possibly to hear complaints. The industry could do much to refurbish its own image by establishing a foundation independent of any individual company to help finance research studies of the safety and efficacy of drugs. The more extravagant promotional activities should, we believe, no longer be seen as acceptable. It is up to individual doctors to make that plain.

1 Taggart HMcA, Alderdice JM. Fatal cholestatic jaundice in elderly patients taking benoxaprofen. Br Med f 1982;284:1372.

"House of Commons Official Report (Hansard) Parliamentary Debates. Drug promotion. London: HMSO, 1983:col 1130. (Thursday 27 Jan 1983.)

${ }^{3}$ Informal Working Group on Effective Prescribing. Report to the Secretary of State for Social Services. London: DHSS, 1983. (Greenfield Report.)

4 House of Commons Official Report (Hansard) Parliamentary Debates. Drug safety. London: HMSO, 1983:col 1117. (Thursday 27 Jan 1983.)

5 Anonymous. Crying wolf on drug safety. Br Med f 1982;284:219-20.

- Association of the British Pharmaceutical Industry. Code of practice for the pharmaceutical industry. Data sheet compendium. London ABPI, 1981-2:vi-xiii

\section{Excessive sweating of the palms and armpits}

Laymen often use the handshake as a test of personality: to

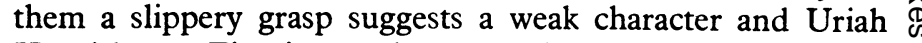
Heepishness. First impressions, especially those based on such a crude parody of the lie detector test, are not always right; but if weakness means a poorer ability to cope with stress and a greater tendency to withdraw from it than "normal" controls some support for the idea has seemed to come from a recent study of hyperhidrotics. ${ }^{1}$ The numbers were small, however, and the "normal" controls were a group of applicants to $\stackrel{\mathbb{Q}}{\varrho}$ medical school, a breed selecting themselves to take on stress and perhaps not representative of the whole population. In fact, lie detectors uncover anxiety rather than untruths; and though patients with anxiety neuroses do have above average $\vec{\omega}$ spontaneous activity of the sweat glands ${ }^{2}$ the reverse association cannot be taken for granted. Indeed, doctors who have dealt with large numbers of patients with sweaty hands detected few psychiatric disturbances apart from worry over their unpleasant symptoms. ${ }^{3} 4$

These symptoms may be crippling socially and need sym- of pathetic and skilled management-even if they are due only to production of sweat at the upper limit of a range of normality and hardly ever to any underlying medical disorder. The same applies to the owners of sweaty armpits, who strongly dislike $\vec{\theta}$ the minor waterfalls which trickle down the sides of their $\mathbb{D}$ chests, soaking, staining, and even rotting their clothing.

Perhaps only a man named Shelley could write enthusiastic- $\frac{\stackrel{\rho}{2}}{2}$ ally (let alone poetically) about the armpit and its effluents. $\vec{\bullet}$ Shelley and his colleague Hurley have recorded their campaign for axillary dryness over the years in a series of sparkling papers. In 1963, frustrated by the failure of conservative measures in the most severe cases, they devised a simple operation to remove a conveniently small area of skin from the vault of the axilla, where most of the active sweat glands are to be found. $5 \stackrel{\varnothing}{\varnothing}$ The glands can be mapped out preoperatively with starch and $\vec{F}$ iodine, but excision of much of the hair bearing area also gives $\frac{\rho}{3}$ good results. ${ }^{6}$ Most patients have been delighted-despite some problems with postoperative infection and restriction of shoulder movements. Sometimes the scars become wide ${ }^{7}$-but they are well hidden, and the technique can be modified to overcome this. ${ }^{8}$ Other methods of damaging the glands, such $\div$ as cryotherapy ${ }^{9}$ and subcutaneous curettage, ${ }^{10}$ did not supplant the Hurley-Shelley operation, which rightly kept its popularity $ᄋ$ until 1975-when its inventors came up with another solution to what they called "the riddle of the axilla."

Why, they asked, do topical antiperspirants, effective on $N$ other areas of skin, work so poorly in the armpit? The answer $D$ lies in the sweat itself, which is so profuse there that it dilutes and washes them away. To get round this they revived ${ }_{0}$ aluminium chloride hexahydrate, long known to be an effective antiperspirant but one which had been discarded as intolerably irritant in aqueous solution owing to the formation of hydro- 0 chloric acid. Made up to $20 \%$ or $25 \%$ in absolute alcohol (quite strong enough to dissolve metal buckets ${ }^{11}$ and pass- ${ }^{+}$ ports ${ }^{12}$ ), and applied at night because the sweat glands switch $\frac{0}{0}$ off during sleep, this compound has proved to be highly $\underset{\mathbb{D}}{\mathbb{D}}$ successful. ${ }^{13}$ Irritation of the skin may be a problem, but luckily $\frac{?}{\mathbb{P}}$ the polyethylene occlusion that was originally recommended is often not needed. The armpit should not be shaved just before the application, and $0.5 \%$ hydrocortisone cream helps if $\frac{0}{0}$ irritation is still a nuisance. The aluminium salt takes some three weeks to dissolve, and proprietary preparations with $\frac{0}{\partial}$ 